\title{
0 processo estrutural e a maximização da tutela jurisdicional: uma visão policêntrica
}

https://doi.org/10.21814/uminho.ed.30.20

\author{
Marcílio Barenco Corrêa de Mello \\ Procurador do Ministério Público de Contas do \\ Estado de Minas Gerais/Brasil
}

\section{Introdução}

O presente paper - em via estreita - atenta às transformações e diretrizes globais na busca de soluções maximizadas para múltiplos problemas que envolvam à busca da efetivação de direitos pela via da tutela jurisdicional, calcada no ideário da inafastabilidade do controle jurisdicional.

O modelo processual clássico erigido para abarcar demandas individuais, necessita de ressignificação para incutir nova visão policêntrica, toda vez que o meritum causae envolva questões estruturais irradiantes, cujo pano de fundo seja a violação massiva de interesses decorrentes de problemas estruturais, que orbitam na seara transcendente de interesses personalíssimos (i.e. interesses gerais), onde o papel do Poder Judiciário apresenta sobrelevo para conformar resoluções de demandas multipolares, cuja eficácia prestigie o transindividualismo em soluções estruturantes.

Assim, além de estancar a tutela individual repetitiva substituída por uma solução irradiante concertada, servirá de vetor de insegurança jurídica em causas de maior complexidade (policêntricas), cuja decisão decorra efeitos somente inter pars.

O modelo tradicional de formação da relação jurídica processual, com a polarização processual entre autor e réu, cujos efeitos decisórios alcancem somente as partes do processo judicial exige ressignificação, não se apresentando como iter procedimental suficiente capaz de estabilizar as relações jurídicas plúrimas que envolvam demandantes multifacetados, vertidos direitos policêntricos (coletivos).

Nesse particular, o processo estrutural surge como forma idônea ao conduto de decisões judiciais que deem ensejo à solução de controvérsias de mérito de forma aberta e irradiante, alcançado plúrimos casos idênticos de pretensão resistida, em proteção simultânea de uma gama de interesses e direitos individuais, tudo por meio de neófitos dogmas processuais civis. 
Sem prejuízo, deve-se atentar às restrições impostas aos órgãos judiciários para adentrar em questões de mérito de direito coletivo, onde residam estrita competência deferida aos outros poderes (legislativo e executivo).

Hão de surgir, com a implantação dos ideários dos processos estruturantes, medidas contentivas da ineficiência da máquina pública para suportar a cultura demandista complexa, que busca cada vez mais do Estado a satisfação de um enorme rol de direitos individuais conquistados por lutas históricas, mas, hodiernamente, impossibilitados de compleitude assistencialista pela escassez de recursos disponíveis.

Numa decisão estruturante coletiva, num cenário de maximização da atuação do Estado-juiz com proferimento de decisão de efeitos irradiantes, dotar-se-á a tutela deferida de maior segurança jurídica e definitividade, propiciando-se a (con)formação legítima dos elementos nucleares das funções típicas judiciárias - órgão protetivo de direitos e garantidor da pacificação social -, com a entrega de decisões de mérito a produzir uma concertação da eficácia de interesses e direitos, a impor a mudança da postura com vistas a expurgar a violação massiva e reiterada advinda de um estado de coisas em desconformidade ${ }^{1}$.

\section{DO PROCESSO JURISDICIONAL CLÁSSICO}

O processo jurisdicional clássico é caracterizado pelo princípio da inércia ou da demanda, onde, após provocada a função jurisdicional pela via do processo residirá clara bipolarização de partes (autor e réu), pedido antagônico de contendores, tutela jurídica de viés retrospectivo e episódico (abarcando fatos pretéritos), além de possuir foco em decisão de mérito declaratória, constitutiva ou condenatória (sanção) com efeito entre as partes.

Nesse diapasão, deflagrado o processo contencioso por provocação de um interessado em satisfação de direito submetido à pretensão resistida, romper-se-á a inércia do órgão judiciário, desenvolvendo-se o procedimento pela via do impulso oficial submetido às regras adjetivas vigentes.

Já sob o enfoque dos sistemas processuais, sob uma feição publicista, as características principais do processo clássico se darão com a oralidade e a concentração de provas (audiência de instrução e julgamento), onde o desenvolver das fases advirá ex officio, com ativismo judicial em matéria probatória na busca da verdade material, mantendo-se a imparcialidade do julgador. Em sede de procedimento, o processo judicial desvela-se como sistema de regras adjetivas e de formas procedimentais (legalidade formal processual), caracterizado pela rigidez dessas formas, em detrimento a uma ideia de liberdade das formas.

1 GALDINO, Matheus Souza - Breves reflexões sobre as consequências de uma compreensão teleológica dos fatos para a teoria do processo estrutural. In ARENHART, Sérgio Cruz; JOBIM, Marco Félix (Org) - "Processos estruturais". 2. ${ }^{a}$ ed. Salvador: Juspodivm, 2019, pp. 705-706. 
Assim, caracteriza-se pela existência de procedimento rígido, minudentemente descrito, onde os sujeitos processuais (partes) devem seguir um roteiro previamente estabelecido, sem possibilidade de alternativas ou "atalhos", tudo sob fundamento de uma garantia individual de estrita segurança jurídica num "devido processo legal”, que age precipuamente como vetor de eventuais arbítrios jurisdicionais e de qualquer das partes.

Nesse contexto de publicidade processual e excesso de formalismo, limitaram-se os poderes do juiz, impulsionando o engajamento das partes na tramitação dos processos em que litigam². Em linha de pensamento romano-germânico (civil law), as normas gerais e abstratas estabelecidas na lei adjetiva também surgem como vetoras à vontade das partes e dos arroubos aos arbitrários judicantes. Contudo, tais "amarras" garantidoras da proteção da confiança e da segurança jurídica, passam a impedir os consentâneos lógicos do processo em si (instrumentalidade), confrontando-se com os ideários de autonomia do ramo do direito processual ${ }^{3}$.

Sob um viés instrumental, a participação do juiz no processo - ativamente - se deu por critérios de justiça e equidade, mantendo-se sempre a imparcialidade, a proteção da confiança e a segurança esperada pelas partes, posto que o presidente dos trabalhos é detentor de fé pública no exercício de seu munus; além disso, propiciou a flexibilização procedimental por ajustes volitivos entre as partes, desde que não decorrente de mitigação do contraditório judicial e sob fiscalização do próprio juiz .

Deste modo, as estritas balizas de vinculação das partes às formas procedimentais, deu lugar a uma primazia da maior efetividade da tutela jurisdicional (maximização), possibilitando-se, inclusive, a convalidação de vícios formais desde que "não graves", isto é, possivelmente sanáveis ${ }^{5}$.

Em apertada síntese, a transição das bases processuais vinculadas ao formalismo procedimental para os fins da tutela jurisdicional em maximização, instrumentalizam não só o exercício do contraditório em todas as suas etapas, ainda que presente o acordo e o consenso, mas, sobretudo, por dever de colaboração das partes que poderão influir em seu desfecho satisfativo, internalizando-se de vez os ideários constitucionais do processo jurisdicional democrático.

\section{DO PROCESSO ESTRUTURAL}

O processo estrutural é aquele que trata de uma lide complexa (não essencial) decorrente de um problema estrutural, que visa sanar de forma irradiante um estado

2 GRECO, Leonardo - Publicismo e privatismo no processo civil. "Doutrinas Essenciais de Processo Civil". [s.i.]. Vol. 1, [s.n.] (2011), pp. 1221-1254.

3 AMENDOEIRA Jr., Sidney - Fungibilidade dos meios. São Paulo: Atlas, 2008, pp.14-15.

4 GAJARDONI, Fernando Fonseca - Flexibilização procedimental: um novo enfoque para o estudo do procedimento em matéria processual, de acordo com as recentes reformas do CPC. São Paulo: Atlas, 2008, pp. 86-87.

5 Art. 932, § único e art. 1.029, § 3º, do Código de Processo Civil brasileiro. 
desconforme de $\operatorname{coisas}^{6}$ (institucional), caracterizado pela multipolaridade das partes (policentria) que litigam acerca de interesses interligados coletivamente (não necessariamente conflitantes), sob viés prospectivo e pontual, de tudo visando uma readequação procedimental com foco na reestruturação dos meios e de sempre de natureza consequencialista.

Trata-se de uma neófita espécie do gênero de processo jurisdicional coletivo, pelo qual se pretende reorganizar uma estrutura burocrática - pública ou privada -, que ocasiona, fomenta ou permite, pelo modo que funciona, uma violação massiva de interesses e direitos, a originar a ideia de um litígio estrutural?.

Para tal, é dependente da aceitação dos conceitos de relativização das preclusões processuais, de relativização das balizas clássicas da coisa julgada material, e da flexibilização da fase cumprimentória do julgado, a permitir, inclusive, o entranhamento de ideários da consensualidade, tudo após o juiz ter proferido decisão de mérito estrutural.

Assim, partindo de uma tipificação tipológica ${ }^{8}$, o processo estrutural possui características próprias, a saber: (i) recai sobre um problema estrutural que ocasiona um estado de coisas ilícito ou uma desconformidade estrutural; (ii) perquire uma transição desse estado de coisas desconformes a um estado ideal de coisas ${ }^{9}$ (restruturação institucional), com um escalonamento de soluções parciais até atingimento de seu fim; (iii) desenvolve-se em procedimento bifásico (conhecimento e executivo), onde no primeiro se reconheça e declare a existência do problema estrutural (decisão de mérito), e no segundo, se estabeleça projeto de reestruturação a ser implementado (fase cumprimentória); (iv) desenvolve-se num procedimento flexível endoprocessual, com admissibilidade de participação de terceiros interessados (forma atípica de intervenção de terceiros) e com medidas interlocutórias executivas, com a possibilidade de modificação do objeto do litígio e utilização de mecanismos de cooperação judiciária; e, por fim, (v) entroniza elementos de consensualidade adaptativos ao processo executivo.

Como objetivo imediato e foco para alcance do estado de coisas ideal, o processo estrutural sobreleva a investigação de causa do problema e de seu efeito deletério,

6 Cf. GALDINO, Matheus Souza - Elementos para uma compreensão tipológica dos processos estruturais. Dissertação de Mestrado. Salvador: Universidade Federal da Bahia (UFBA), 2019, pp. 125-130. Ainda, GALDINO, Matheus Souza - Breves reflexões sobre as consequências de uma compreensão teleológica dos fatos para a teoria do processo estrutural. In ARENHART, Sérgio Cruz; JOBIM, Marco Félix (Org) - "Processos estruturais". 2. ${ }^{a}$ ed. Salvador: Juspodivm, 2019, pp. 705-706.

7 Cf. VITORELLI, Edilson - Levando os conceitos a sério: processo estrutural, processo coletivo, processo estratégico e suas diferenças. "Revista de Processo". São Paulo: Thomson Reuters. Vol. 284, [s.n.] (2018), pp. 333-369.

8 DIDIER JUNIOR, Fred; ZANETI JUNIOR, Hermes; OLIVEIRA, Rafael Alexandria de - Elementos para uma teoria do processo estrutural aplicada ao processo civil brasileiro. "Revista do Ministério Público do Estado do Rio de Janeiro. Rio de Janeiro". [s.i.]. nº 75 (2020), pp. 107-108.

9 GALDINO, Matheus Souza - Elementos para uma compreensão tipológica dos processos estruturais. Dissertação de Mestrado. Salvador: Universidade Federal da Bahia (UFBA), 2019, pp. 125-130. 
"mirando" na sua supressão no futuro, a projetar um caminho que deve ser percorrido para alcançá-lo (relação entre meio e fim) ${ }^{10}$. Nesse sentir, busca-se elidir o estado de coisas desconforme (ilícitas ou não), promovendo-se uma transição para o estado de regularidade das coisas.

Por fim, um decisão de mérito estrutural é aquela que partindo do reconhecimento de um problema estrutural determina sua reestruturação por meio de um programa de ações concertadas, a fim de, consequencialmente, suprima problemas complexos e irradiantes preexistentes e que ocasionam o malferimento a interesses e direitos públicos ou privados.

\section{CONCLUSÃO}

Os processos estruturais são mais aptos para adjudicação de litígios complexos ou irradiados. Representam novo modelo processual volvido à solução de lides de alto grau de conflituosidade, onde, além das partes envolvidas no litígio, os atores interessados extraprocessuais protagonizam participação na resolução mais adequada do conflito (multipolaridade de partes), garantindo-se maior aceitação psicológica no restabelecimento de interesses massivamente violados, a promover mudanças estruturantes institucionais e sociais.

Além de servir de técnica de racionalização administrativa, o mecanismo estrutural alberga a reestruturação de instituição social pública ou privada, responsável pela violação reiterada de valores ditos públicos ou privados de interesses relevantes. A extensão dos efeitos do decisum para além das partes endoprocessuais, insere "interessados" que devam contribuir para resolução da demanda ou cumprimento da adjudicação, sendo capaz de congregar interesses mutáveis e contraditórios (ou não), onde residem uma multiplicidade de tensões dispersas e concorrentes.

A tutela jurisdicional decorrente da relação jurídica processual estruturante caracteriza-se pela continuidade, prospecção e maleabilidade, onde a decisão de mérito guardará não um termo da controvérsia ensimesmada, mas a deflagração de um novo marco relacional entre juízo, instituição e sociedade, todos debruçados sobre o litígio na fase cumprimentória.

Dada a alta complexidade do cumprimento da decisão, a imposição do Estado-juiz não seria capaz - per si - de estabilizar as relações jurídicas encetadas inter pars, a fomentar uma multiplicidade litigiosa em detrimento da eficiência e celeridade do agir estatal.

Nesse cenário de participação colaborativa das partes e de interessados irradiados na solução do conflito, o foco adjudicatório se desloca da reparação do direito violado à reestruturação institucional, a incidir sobre modus operandi da transgressão

10 GALDINO, Matheus Souza - Breves reflexões sobre as consequências de uma compreensão teleológica dos fatos para a teoria do processo estrutural. In ARENHART, Sérgio Cruz; JOBIM, Marco Félix (Org) - "Processos estruturais". 2. a ed. Salvador: Juspodivm, 2019, pp. 698-704. 
massiva, atacando-se à causa e não a consequência da reiterada irregularidade vergastada, a flexionar a razoabilidade, adequação, proporcionalidade e eficiência em maximização dos efeitos da tutela estatal

Criará um ambiente de maior racionalização administrativa perante os Tribunais - espancando demandas individuais repetitivas -, quer estabelecendo critérios de adequada segurança jurídica como novo mecanismo estruturante idôneo de pacificação social.

O modelo de processo estruturante como técnica de maximização da tutela jurisdicional implica na reformulação (e aceitação) de novas balizas das condições da ação e dos efeitos do julgado, quando o objeto do litígio verse sobre problemas estruturais de alta conflituosidade e complexidade visando o cumprimento do julgado.

Dever-se-á inflexionar o princípio da demanda, as preclusões processuais e a coisa julgada, tudo a propiciar um ambiente de maleabilidade cooperativa, onde o julgado será indutor da solução dialógica e segura da demanda, por meio da consensualidade e participação colaborativa de todos os envolvidos e interessados irradiados, desaguando na reestruturação institucional capaz de atacar as causas da violação massiva de direitos, restabelecendo-os, em via de consequência, um estado de coisas ideal. 
ARENHART, Sérgio Cruz - A prova estatística e sua utilidade em litígios complexos. In "Revista Direito e Práxis". Rio de Janeiro. Vol. 10, n. ${ }^{1}$ (2019).

-. Processo multipolar, participação e representação de interesses concorrentes. In ARENHART, Sérgio Cruz; JOBIM, Marco Félix (Org.) - "Processos estruturais". 2. a ed. Salvador: Juspodivm, 2019.

- Processos estruturais no direito brasileiro: reflexões a partir do caso da ACP do carvão. In "Revista de Processo Comparado". São Paulo: RT. [s.i.], n. 2 (2015).

- Decisões estruturais no direito processual civil brasileiro. In "Revista de Processo". São Paulo: RT. Vol. 225, A. 38 (2013).

ASSIS, Araken de - Cumprimento da sentença. Rio de Janeiro: Forense, 2006.

BATISTA, Felipe Vieira - A recuperação judicial como processo coletivo. Dissertação de Mestrado. Salvador: Universidade Federal da Bahia (UFBA), 2017.

CABRAL, Antonio; ZANETI JUNIOR, Hermes - Entidades de infraestrutura específica para a resolução de conflitos coletivos: as claims resolution facilities e sua aplicabilidade no Brasil. In "Revista de Processo". São Paulo: RT. Vol. 287, [s.i.] (2019).

COSTA, Eduardo José da Fonseca - A "execução negociada" de políticas públicas em juízo. In "Revista de Processo”. São Paulo: RT. Vol. 212, A. 37 (2012).

DIDIER JR., Fredie; CABRAL, Antonio do Passo; CUNHA, Leonardo Carneiro da - Por uma nova teoria dos procedimentos especiais. Salvador: Juspodivm, 2018.

DIDIER JR., Fredie; CABRAL, Antonio do Passo; OLIVEIRA, Rafael Alexandria de - Notas sobre as decisões estruturantes. In ARENHART, Sérgio Cruz; JOBIM, Marco Félix (Org.) - "Processos estruturais". 2. ${ }^{a}$ ed. Salvador: Juspodivm, 2019.

FERRARO, Marcella Pereira - Do processo bipolar a um processo coletivo-estrutural. Dissertação de Mestrado. Curitiba: Universidade Federal do Paraná (UFPR), 2015.

FISS, Owen. Two models of adjudication. In DIDIER JR. Fredie; JORDÃO, Eduardo Ferreira (Coord.). Teoria do processo: panorama doutrinário mundial. Salvador: Juspodivm, 2008.

GALDINO, Matheus Souza. Breves reflexões sobre as consequências de uma compreensão teleológica dos fatos para a teoria do processo estrutural. In ARENHART, Sérgio Cruz; JOBIM, Marco Félix (Org.) - "Processos estruturais". 2. ${ }^{\text {a }}$ ed. Salvador: Juspodivm, 2019.

—. Elementos para uma compreensão tipológica dos processos estruturais. Dissertação de Mestrado. Salvador: Universidade Federal da Bahia (UFBA), 2019.

JOBIM, Marco Felix. A previsão das medidas estruturantes no artigo 139, IV, do novo Código de Processo Civil brasileiro. In ZANETI JUNIOR, Hermes (Coord.) - Repercussões do novo CPC - processo coletivo. Salvador: Editora Juspodivm, 2016

- Medidas estruturantes: da Suprema Corte Estadunidense ao Supremo Tribunal Federal. Porto Alegre: Livraria do Advogado Editora, 2013.

LAMÊGO, Gustavo - Técnicas de cooperação judiciária aplicadas a processos estruturais. Monografia de conclusão de curso de graduação em Direito. Salvador: Universidade Federal da Bahia (UFBA), 2019.

VITORELLI, Edilson - Litígios estruturais: decisão e implementação de mudanças socialmente relevantes pela via processual. In ARENHART, Sérgio Cruz; JOBIM, Marco Félix (Org.) - Processos estruturais. 2. ${ }^{a}$ ed. Salvador: Juspodivm, 2019.

- Levando os conceitos a sério: processo estrutural, processo coletivo, processo estratégico e suas diferenças. “Revista de Processo". São Paulo: Thomson Reuters. Vol. 284. [s.i.] (2018), pp. 333-369.

- O devido processo legal coletivo: dos direitos aos litígios coletivos. 2. ${ }^{a}$ ed. São Paulo: Thomson Reuters Brasil, 2019. 